\title{
CRÍTICA AO IDEÁRIO NEOLIBERAL NA EDUCAÇÃO: PRECARIZAÇÃO E DESCARACTERIZAÇÃO DA ESCOLA PÚBLICA PAULISTA
}

\begin{abstract}
José Luis Derisso ${ }^{1}$
Rita de Cássia Duarte ${ }^{2}$

\section{Resumo}

O presente artigo tem como objetivo abordar o processo de precarização e descaracterização da escola pública paulista no contexto da aplicação sistemática de políticas neoliberais - no quadro de um projeto de reformas do estado e da educação brasileira desencadeadas a partir de meados da década de 1990 - e problematizá-lo à luz da concepção de educação e de escola pública da Pedagogia Histórico-Crítica (PHC). Priorizou-se a rede oficial de ensino paulista, em nível de educação básica, por sua condição de maior sistema público de ensino do país bem como pela própria importância econômica e política do estado de São Paulo no cenário nacional. Neoliberalismo, reforma do Estado e da Educação, precarização do trabalho docente e descaracterização da educação escolar no que tange aos seus fins constituem ingredientes de uma mesma concepção de educação e de sociedade que a PHC tem todo o aporte teórico para criticar e se contrapor, justamente porque sua concepção de sociedade, de formação do indivíduo, de educação e de papel social atribuído à escola é diametralmente oposta e antagônica à do ideário neoliberal.
\end{abstract}

Palavra-chave: Precarização do trabalho docente. Estado de São Paulo. Políticas educacionais. Pedagogia histórico-crítica.

\section{CRITICISM TO THE NEOLIBERAL IDEAS IN EDUCATION: PRECARISATION AND DECHARACTERIZATION OF THE PUBLIC SCHOOL IN THE STATE OF SAO PAULO}

\begin{abstract}
The present article aims to address the process of precarization and decharacterization of the public school from Sao Paulo in the context of the systematic application of neoliberal policies - within the framework of a project of reforms of the Brazilian state and education that began in the mid 1990s - and problematizing it in the light of the conception of education and public school of Historical-Critical Pedagogy (PHC). The official education network of the state of São Paulo was prioritized, at basic school level, due to its condition of greater public education system in the country as well as the economic and political importance of the state of São Paulo in the national scenario. Neoliberalism, State and Education reform, the precariousness of the teaching work and the lack of characterization of school education in relation to its aims are ingredients of the same conception of education and society that PHC has all the theoretical support to criticize and oppose, precisely because its conception of society, the formation of the individual, education and social role attributed to the school is diametrically opposed and antagonistic to that of the neoliberal ideology.
\end{abstract}


Keywords: Precariousness of teaching work. State of Sao Paulo. Educational policies. Historical-critical pedagogy.

\section{NEOLIBERALISMO E REFORMAS}

Tem se tornado praticamente impossível refletir sobre a escola pública no que tange às condições de trabalho (salário, jornada, saúde, carreira docente, etc...) e à orientação pedagógica desassociado das políticas públicas que vêm sendo aplicadas sob a orientação geral de um receituário, que via de regras e apresenta como agenda necessária para a resolução de cada um dos problemas de ordem econômica vivenciados pelo país.

Essa orientação vem se impondo desde o início da Reforma do Estado na metade da década de 1990, no Governo de Fernando Henrique Cardoso, cuja origem no plano internacional deve ser situada num contexto social e econômico mais amplo, face às mudanças conjunturais ocorridas em função da chamada reestruturação produtiva do capital, a partir do final da década de 1970, na retomada do liberalismo (neoliberalismo) com as crises do chamado "socialismo real" e do estado de bem estar social (WelfareState).

As políticas de Reforma do Estado decorrem das orientações do chamado "Consenso de Washington" expresso num documento produzido pelo Fundo Monetário Internacional (FMI) e Banco Mundial juntamente com o Departamento de Tesouro dos Estados Unidos com o fim de implementar nos países tidos como "em desenvolvimento" ou "emergentes" o enquadramento de suas administrações e economias às necessidades e pretensões do capitalismo internacional na perspectiva do ideário neoliberal.

A reestruturação produtiva assim como a orientação neoliberal acentuou o nível de dependência dos países periféricos do sistema para com as grandes potências capitalistas no tocante ao abastecimento de produtos básicos e de empréstimos financeiros, uma vez que estas concentram a maior parte da riqueza mundial ao mesmo tempo em que dominam o mercado internacional. A este fenômeno, segundo Deitos (2008, p. 23) convencionou-se “[...] chamar de globalização, processo sustentado politicamente pelo neoliberalismo [...]", uma resposta do capital "[...] para dar conta de uma fase da crise estrutural do capitalismo atual".

É nesse contexto de globalização que

[...] a economia, a sociedade, o estado e as políticas sociais no Brasil são concebidas, imbricando os interesses internos e externos, sob o controle social das classes hegemônicas nacionais, consolidando-se a alternativa liberal no país e intensificando o processo de internacionalização da economia e do estado brasileiro. (DEITOS, 2008, p. 23).

Visando a inserção na nova ordem econômica globalizada, coube aos países periféricos adotarem políticas de ajuste de teor nitidamente neoliberal que apontam para a retração do tamanho do Estado, por meio, principalmente, da redução de gastos públicos com as áreas sociais e da diminuição de diretos sociais da classe trabalhadora.

Na lógica neoliberal de "modernização" do Estado para satisfazer às demandas da 
Artigo

doi: $10.20396 /$ rho.v17i4.8651218

globalização, aparecem como soluções para diminuir o tamanho do Estado as privatizações das empresas estatais e a terceirização dos serviços públicos por meio das Parcerias PúblicoPrivadas (PPP), que consistem em transferir para a iniciativa privada a responsabilidade de gerir serviços que até então eram da competência do Estado. O principal argumento para a aplicação destas medidas é o de que o Estado tem se mostrado ineficiente na gestão do patrimônio público em função da burocracia reinante em seu interior e dos gastos elevados com folha de pagamento, entre outros. Com tal argumento, opta-se pela ruptura com o modelo de Estado que, segundo os reformadores neoliberais, seria assistencialista e burocrático, impondo gradativamente a este Estado um perfil gerencial eficiente, moderno e racional, modelo este que estimularia o crescimento econômico ao baratear os custos de produção e satisfazer as demandas impostas pela mundialização em curso.

Parte-se assim do pressuposto capitalista deque somente existe crescimento econômico na medida em que uma empresa afere lucro e acumula capital, excluindo desse pressuposto todas as formas de satisfação de necessidades que não passam pela relação mercadológica, tais como as atividades mais simples de subsistência; assim como não se reconhecem méritos nos serviços públicos nas áreas de educação, saúde, transporte, assim como nas variadas formas de assistência social aos cidadãos prestadas diretamente pelo Estado e sem o concurso da iniciativa privada. Nesta perspectiva não importa o que se faz, mas o como se faz, sendo que a satisfação das necessidades transforma-se de finalidade da produção social em meio de realização do lucro empresarial, de modo que o termômetro do desenvolvimento econômico passa a ser o engrandecimento do capital e não a qualidade de vida do povo em geral.

Nesse sentido é importante notar que já em meados do século XIX Karl Marx identificava que a economia política clássica, que abordava o fenômeno do ponto de vista da produção e das relações decorrentes da mesma, cedera lugar a economia vulgar que tem por objetivo basicamente a circulação, ou seja, o mercado. De modo que, segundo Marx (apud LUKÁCS, 2010, p. 51),

Agora não se trata mais de saber se este ou aquele teorema é verdadeiro, mas sim se é útil ou prejudicial ao capital, cômodo ou incômodo, contrário aos regulamentos da polícia ou não. Em lugar de pesquisa desinteressada, temos a atividade de espadachins assalariados; em lugar de uma análise científica despida de preconceitos, a má consciência e a premeditação.

No ideário apologético do neoliberalismo lucro e qualidade de vida não se contrapõem, mas ao contrário se complementam, porque a realização do lucro pressuporia o aumento da capacidade de investimento da iniciativa privada, consequentemente de novos empregos e da massa salarial. Porém, esta antiga tese da "mão invisível" do mercado não dá conta de explicar o fato de que o fosso entre ricos e pobres tem aumentado em proporção maior do que o crescimento da produção de riquezas e o milenar problema da fome tem sido, via de regra, remediado por iniciadas assistenciais que emanam principalmente do Estado. Aliás, medidas via de regra condenadas pelos críticos burgueses que relembram o dito popular segundo o qual "não se deve dar o peixe, mas ensinar a pescar".

No contexto da reforma neoliberal do Estado, coube à educação pública um lugar de destaque, a Escola ganhou uma nova caracterização e ficou, em certa medida, refém de intervenções, sobretudo dos organismos internacionais - Banco Mundial e FMI - que 
impõem condições pautadas no princípio empresarial da eficiência e qualidade para a liberação de financiamentos para a educação dos países "em desenvolvimento". Na visão destes organismos internacionais o processo de expansão da escola não acompanhou a qualidade do serviço prestado e isto teria ocorrido pela incompetência dos profissionais,

\begin{abstract}
Logo a escola carece de uma ampla reforma administrativa. Dessa forma, de acordo com as tecnocracias neoliberais, não há falta de escolas, não há falta de professores. O que falta são escolas mais eficientes e professores mais competentes, além do que, para sanar tal crise, não há falta de investimento de recursos. O que falta é um melhor gerenciamento dos recursos existentes. (ZANARDINI, 2008, p. 64).
\end{abstract}

As instituições financeiras internacionais, notadamente o Banco Mundial, norteiam suas "orientações" pela lógica do mercado, abordando a questão educacional num sentido estritamente pragmático, ou seja, o de produzir resultados quantificáveis, propondo soluções eminentemente técnico-racionais, chegando assim a um modelo escolar caracterizado por "duas grandes ausências: os professores e a pedagogia", um modelo que se configura "[...] em torno de variáveis observáveis e quantificáveis [...] que não comporta os aspectos especificamente qualitativos, ou seja, aqueles que não podem ser medidos, mas que constituem, porém, a essência da educação". (TORRES, 2000, p. 139).

É sobre este prisma que a partir do ano de 1995 se dá a implantação de uma ampla reforma educacional no estado de São Paulo que, apesar da aparência e de um discurso pretensamente democrático, não levou em conta as demandas e reinvindicações dos diferentes grupos diretamente interessados na melhoria da educação pública. Nesse sentido, esta reforma foi acompanhada de medidas autoritárias que ensejaram discordâncias e resistências, medidas que apesar do apelo ao senso comum e amplo apoio midiático não lograram evitar os conflitos.

Foi a partir dessa reforma educacional que presenciamos um grande avanço no processo de precarização do trabalho docente, bem como na descaracterização do trabalho educativo e no desvirtuamento da função da escola.

\title{
PRECARIZAÇÃO DO TRABALHO DOCENTE NAS ESCOLAS PÚBLICAS DO ESTADO DE SÃO PAULO
}

A reforma do Estado visa atender às necessidades do mercado internacional globalizado. O foco principal da orientação dos organismos multilaterais, que no caso da educação brasileira diz mais respeito ao Banco Mundial que é quem financia projetos, é a desoneração do Estado, apontando para a necessidade de estabelecerem novas funções no sentido de reduzir os gastos públicos e de possibilitar o ingresso gradual da iniciativa privada nas atividades até então de competência estatal, para tanto as privatizações e as PPP. A ideia é que o Estado se desobrigue de manter serviços básicos para a população e que atue somente em áreas tidas, pelo neoliberalismo, como elementares.

Encontramos a justificativa do porque aprofundar a orientação neoliberal num artigo publicado na página oficial da Secretaria de Educação do Estado de São Paulo e assinado pelo próprio secretário da pasta, José Renato Nalini, que sustenta a "tese" de que o modelo 


\title{
Revista HIISTEYIDIR On-line
}

de estado intervencionista e de bem-estar foi responsável por sobrecarregar a nação com encargos e responsabilidades que devem ser abolidas por terem se inviabilizado em termos de sustentação:

\begin{abstract}
Afinal, Estado é instrumento de coordenação do convívio, assegurador das condições essenciais a que indivíduos e grupos intermediários possam atender à sua vocação. Muito ajuda o Estado que não atrapalha. Que permite o desenvolvimento pleno da iniciativa privada. Apenas controlando excessos, garantindo igualdade de oportunidades e só respondendo por missões elementares e básicas. Segurança e Justiça, como emblemáticas. Tudo o mais, deveria ser providenciado pelos particulares. (SÃO PAULO, 2016, grifo nosso).
\end{abstract}

Trata-se de uma fala que, diferente dos discursos eleitorais, desnuda o grande objetivo da Reforma que é o do desmonte dos serviços públicos ao desobrigar o Estado de responsabilidades que não devem ser consideradas como elementares na medida em que se compreende que a vida social se desenrola num mero cenário de competição pelo sucesso, onde o fracasso constitui uma variável inevitável. Mas se, contrariamente aos objetivos perseguidos pelo neoliberalismo, quisermos caminhar para um convívio social no mínimo "menos selvagem", há que se entender que educação, saúde e habitação constituem direitos e não "mimos", conforme entende o Secretário:

A proliferação de direitos fundamentais causou a trivialização do conceito de direito e, com esse nome, começaram a ser exigíveis desejos, aspirações, anseios, vontades mimadas e até utopias. Tudo a ser propiciado por um Estado que se tornou onipotente, onisciente, onipresente e perdeu a característica de instrumento, para se converter em finalidade. (Ibidem).

O fato é que os ataques aos serviços públicos não se apresentam nos discursos oficiais e muito menos nos palanques eleitorais como constituintes de um ideário, um fim-em-si, mas como medidas emergenciais que visam dar fôlego à economia até que se produza um novo surto de crescimento, deixando assim implícito à população que se trata de sacrifício momentâneo, um "apertar os cintos", até a retomada da "normalidade". Em síntese, uma grande ilusão.

Porém, é importante notar que os ataques aos serviços públicos encontram resistências: No final de 2015 o governo paulista optou por uma reorganização da rede estadual que previa o fechamento de 94 unidades escolares para ano letivo seguinte, a resposta foi uma onda de ocupações das escolas pelos estudantes que obrigou a suspensão da medida e culminou com a demissão do então Secretário de Educação, Herman Voorwald (2011-2015).

Se, por um lado, avançam as medidas reformistas, por outro, a resistência a estas mesmas medidas têm barrado ataques - como evidencia o episódio das ocupações das escolas paulistas -, e às vezes até imposto conquistas relativamente aos direitos sociais. $\mathrm{O}$ que somente pode ser explicado porque no cenário em que se desenvolve a Reforma Neoliberal do Estado não existem apenas as vontades das autoridades de Estado legitimadas pelas análises explicativas dos "especialistas" em economia que desfilam nos telejornais -, mas a "indesejável" luta de classes. Caso contrário às medidas do "Consenso de Washington" teriam sido aplicadas uniformemente em todo o mundo naquele mesmo ano de 1989. 


\section{Revista HIIST'TEIDBR On-line}

Artigo

doi: $10.20396 /$ rho.v17i4.8651218

Um resultado emblemático da resistência à tendência de precarização do trabalho docente que tem acompanhado a Reforma foi a aprovação em 2008 da Lei no 11.738 que regulamenta um piso salarial profissional nacional e uma jornada de trabalho menos insalubre para a categoria. Relativamente à jornada do professor, esta lei estabelece que a mesma deva ser constituída por no mínimo um terço de horas-atividade.

Em 2008, ano de aprovação da Lei, o piso salarial estabelecido era de R $\$ 950,00$ por 40 horas semanais para professores com formação de nível médio (no antigo curso Normal ou de Magistério) e em 2016 o mesmo atinge R $\$ 2.135,64$, um aumento de 125\%, fato que foi exaltado a seu tempo pelo então ministro da educação, Aloizio Mercadante, ao declarar que houve um aumento real de $46 \%$ além da inflação. (LUIZ, 2016).

A existência da Lei 11.738/08 encontrou forte resistência em governos de Estado e prefeituras que recorreram da mesma sob o argumento de inconstitucionalidade, mas foram derrotados no plenário do Supremo Tribunal de Federal (STF) em 27 de abril de 2011, data a partir da qual a Lei passou a vigorar.

A indisposição do Governo do Estado de São Paulo para com essa Lei produziu pelo menos dois episódios emblemáticos:

Primeiro, em janeiro de 2012 a Secretaria de Educação do Estado de São Paulo, sob o argumento de aplicar a Lei do Piso no que respeita à exigência de no mínimo um terço de atividade extraclasse, implementou uma jornada de 32 aulas semanais. Para isso utilizou o argumento de que a jornada constitucional é de 40 horas e não de 40 horas/aulas semanais. Esta medida vigora em São Paulo até hoje, ao passo que no Paraná o número de aulas sobre uma jornada de 40 horas do professor é de 26 horas/aulas. O que se explica apenas pela diferença na relação de forças estabelecida entre o Estado e o movimento organizado dos professores nas duas unidades da federação.

Segundo, em janeiro de 2017 o Estado de São Paulo anunciou que cumpriria a Lei 11.738 de modo que o menor salário não ficaria abaixo de $\mathrm{R} \$ 2.298,80$, o correspondente ao valor do piso para este ano - irregularidade se arrastava desde 2015. No entanto, concedeu um abono para os 18.360 profissionais e deixou os outros mais de duzentos mil professores pelo terceiro ano consecutivo sem reajuste salarial. Porém, mediante ação judicial movida pelo APEOESP-Sindicato, O Tribunal de Justiça de São Paulo determinou, seis meses depois, que o governo do Estado de São Paulo deveria conceder reajuste de salário e não abono, porque este último não incide sobre os benefícios (férias, $13^{\circ}$ Salário, vencimento em casa de afastamentos, aposentadoria, etc.).

O recurso da utilização de bônus ao invés de reajuste de salário tem sido uma prática recorrente no estado de São Paulo desde que foi instituído no ano 2000oBônus de Mérito aos docentes e o Bônus Gestão em 2003 para diretores, vice-diretores, coordenadores pedagógicos, supervisores e dirigentes regionais de ensino. Cabe notar que apenas uma parcela dos profissionais podem percebê-los anualmente uma vez que estão vinculados diretamente à aferição de frequência de professores e ao desempenho dos alunos em avaliações institucionais aferidas pelo Sistema de Avaliação do Rendimento Escolar do Estado de São Paulo - SARESP.

Mesmo reconhecendo que os professores de modo geral ganham menos que outros profissionais com nível de formação equivalente, tornou-se de certo modo comum 
considerar que a situação não seria tão grave se considerarmos que a jornada de trabalho do professor é menor e que acaba se constituindo "[...] num forte benefício indireto na escolha da profissão, em especial por parte das mulheres, que podem conciliar as atividades domésticas com o exercício profissional”. (PINTO, 2009, p. 54). O mesmo argumento sustentado por um estudo encomendado pelo Banco Mundial, que analisa a remuneração de professores em 12 países da América Latina declara que se não levarmos em conta a jornada de trabalho dos professores esses tendem a ganhar menos que os demais profissionais com nível superior, mas, se considerarmos a jornada de trabalho dos mesmos,

[...] ocorre uma inversão em boa parte dos países, com exceção de Brasil e Equador de tal forma que, proporcionalmente, os professores passam a ter remuneração mais elevada que seus colegas de outras profissões, e com formação equivalente. (PINTO, 2009 p. 55).

Tais argumentos não levam em conta a especificidade do trabalho docente que não se restringe ao tempo destinado à sala de aula, pois mesmo que o professor tente limitar-se à execução de um roteiro subscrito no livro didático e aplique avaliações cujos resultados possam ser aferidos durante a aula, terá ainda que preparar as tais avaliações, que organizar apontamentos nos diários e estudar o material didático. Porém, o trabalho docente é muito mais do que isto, conforme abordaremos mais à frente.

A evolução do salário dos docentes na rede oficial de ensino do Estado de São Paulo, desde o início das medidas de reforma da educação levam a queixa do sindicato da categoria segundo a qual as perdas salariais desde 1978 situam na casa dos trezentos por cento, e que somente no biênio 2015/2016 ultrapassam a vinte por cento.

Outra medida utilizada pelo Estado de São Paulo e que resulta em rebaixamento da média salarial dos professores e precarização das condições de trabalho foi o fatiamento dos chamados OFA (Ocupantes de Função ou Atividades) que são professores temporários que constituem pelo menos $40 \%$ da totalidade dos professores em exercício. O Estado criou, a partir de 2008, uma diferenciação entre esses professores a partir das denominações de categorias P, F, L, S, O e V. Os professores constituintes destas categorias têm obrigações e direitos diferenciados. Por exemplo: Para a categoria " $F$ " garante-se estabilidade (a partir de uma jornada mínima de 12 horas desde que o professor se submeta a lecionar onde houver aula) e salários e progressões por tempo de exercício muito próximos daqueles percebidos pelos efetivos, porém sem progressões como aquelas relacionadas aos méritos acadêmicos que estes últimos fazem jus. Numa outra ponta da lista temos as categorias "O" (docentes admitidos como temporários após a publicação da LC 1.093/2009), a quem é imposto um limite anual de faltas ao trabalho de 15 dias inclusive para licenças médicas, e "V", que recebem apenas por hora trabalhada com aluno. Para ambas é negado o direito ao credenciamento no Instituto de Assistência Médica ao Servidor Público Estadual - IAMSPE e a qualquer tipo de progressão funcional e salarial.

Frente às perdas salariais e para recompor o poder de compra, a ampliação da jornada de trabalho por meio do acúmulo de dois cargos, que segundo a Constituição pode somar até 64 horas semanais, tem se apresentado como alternativa aos professores paulistas. A partir de 2014, o Estado de São Paulo tem possibilitado que todos os professores, efetivos ou não, ampliem a jornada até o limite constitucional por meio de um segundo contrato empregatício 


\title{
Revista HIISTEYIDIR On-line
}

Artigo

doi: $10.20396 /$ rho.v17i4.8651218

no nível daquele celebrado com a Categoria “O”. De modo que os professores que optarem por esta solução passa a exercer concomitantemente e às vezes na mesma escola duas funções de natureza docente, com remuneração e benefícios distintos.

Submetidos a longas jornadas de trabalho e recebendo quase que exclusivamente o suficiente para uma humilde subsistência com algumas pequenas concessões ao lazer e eventualmente a aquisição de um produto cultural, um cinema ou um livro, o professor tende a mecanizar suas ações exercendo-as acriticamente, ou seja, sobrevivendo na profissão à espera da aposentadoria, sem contar que existem ainda aqueles que recebem abaixo do necessário para a sobrevivência e mais cedo terão que buscar complementação por meio de outra atividade.

Tais condições de trabalho desestimulam os novos professores e também os estudantes das licenciaturas, acarretando a ausência de profissionais em decorrência das demissões no primeiro grupo e da desistência do curso no segundo, sem contar o desestímulo aos novos ingressos nas licenciaturas.

Acerca das demissões por iniciativa do próprio professor, o Jornal o Estado de São Paulo publicou no ano de 2015:

\begin{abstract}
A rede estadual de ensino de São Paulo vive nesse ano uma saída recorde de professores. O corpo docente encolheu $11 \%$ em relação a 2014. A redução ocorreu tanto entre os concursados $(-6 \%)$ como entre os não efetivos $(-16 \%)$ segundo dados da Secretaria de Educação do governo Geraldo Alckmin (PSDB) [...] A redução do número de professores é a maior desde 1999. (TAKAHASHI, 2015).
\end{abstract}

Porém, se as exonerações constituem um indicador da crise, outros fenômenos também podem nos servir de indicadores, entre os quais vislumbramos o vertiginoso crescimento do número de afastamentos médicos decorrentes de doenças laborais resultantes das condições insalubres nas quais se desempenham as atividades docentes:

Uma pesquisa do Sindicato dos Professores do Ensino Oficial do Estado de São Paulo (Apeoesp) revela que dos $40 \%$ dos professores afastados por problemas de saúde, quatro tiveram algum tipo de transtorno psiquiátrico. Os diagnósticos mais comuns foram ansiedade e depressão. O problema é agravado, segundo os docentes, pelo excesso de trabalho e pela falta de respeito na sala de aula.

[...] O estudo revelou ainda que 59\% dos educadores com depressão não têm acompanhamento médico regular. Para o diretor da Apeoesp em Araraquara (SP), o excesso de trabalho é um dos vilões. "A maioria dos professores tem dupla ou tripla jornada de trabalho, muitas vezes ultrapassando 11 horas de trabalho com aluno e isso certamente não é recomendável". (G1 SÃO CARLOS ARARAQUARA, 2012).

Pode-se constatar que o exercício da profissão docente sob condições tão adversas como as existentes na rede oficial paulista é cheio de percalços que constituem motivos para descontentamentos e desilusões pessoais ou coletivas. A realização de uma greve com 92 dias de duração no ano de 2015 constitui evidência da insatisfação no plano coletivo, ao passo que as doenças laborais a evidencia no plano pessoal.

\section{A DESCARACTERIZAÇÃO DA ESCOLA PÚBLICA}




\section{Revista HIIST'TEIDBR On-line}

Artigo

doi: $10.20396 /$ rho.v17i4.8651218

A escola pública estatal, com a abrangência que conhecemos hoje, constitui uma conquista que se impõe a partir da grande Revolução Francesa de 1789 a partir da concepção de que a educação constitui um direito de todos e de que somente por meio do conhecimento científico a humanidade poderia se emanciparem relação à natureza e aos preconceitos vigentes.

Naquele contexto, Condorcet foi um dos filósofos iluministas que mais expressou a pretensão de desmistificar as interpretações dominantes naquela época - em sua obra $O$ esboço de um quadro histórico dos progressos do espírito humano afirma que "[...] o estudo dos fatos sociais foi, por muito tempo, abandonado ao acaso, à avidez dos governos, à astúcia dos charlatães, aos preconceitos ou aos interesses de todas as classes poderosas". (LÖWY, 2009 , p. 22). As classes poderosas a que se referia Condorcet eram a nobreza feudal e o clero, forças sociais cujos poderes persistiam, com formas alteradas, apesar das transformações operadas na sociedade europeia durante a Idade Moderna. Esta mesma crença nas possibilidades do conhecimento embasou sua concepção de escola na elaboração do projeto que deu origem à lei sobre a organização da instrução pública na França de 1792.

A partir da metade do século XX, com a industrialização de vários países europeus e dos Estados Unidos da América, tem lugar a formação dos sistemas nacionais de ensino que foram inspirados no princípio de que a educação consiste em direito de todos e dever do Estado. Um direito que "[...] decorria do tipo de sociedade correspondente aos interesses da nova classe que consolidara no poder: a burguesia" para "[...] construir uma sociedade democrática" e "[...] consolidar a democracia burguesa", sendo que para isso seria "[...] necessário vencer a barreira da ignorância". (SAVIANI, 1997, p. 17). Percebemos que se mantém, de certo modo, a mesma perspectiva pela qual Condorcet defendia a objetividade das ciências sociais, para fazer frente às classes poderosas do Antigo Regime.

Porém, as expectativas revolucionárias que a burguesia depunha na educação, e mais particularmente na escola, começam a se esvair na medida em que esta classe consolida seu poder no plano político - o potencial de oposição da nobreza e do clero à ordem capitalista e ao estado burguês torna-se quase nulo após 1848 - e que, simultaneamente, ocorre a entrada do proletariado na cena política com reivindicações próprias e projetos que buscavam dar continuidade no plano social aos avanços que a burguesia tinha conquistado com a Revolução Francesa no plano jurídico, porque o movimento operário já percebia que a igualdade perante a lei não garantia a igualdade de fato e que o direito à propriedade não garantia o acesso indistinto a ela.

No contexto de 1848, a burguesia não mais necessitava da revolução e muito menos do apoio das classes populares para exercer sua dominação, pois seus principais oponentes, conforme já dissemos, não são mais as velhas ordens do Antigo Regime, mas o proletariado e outros seguimentos da classe trabalhadores que se colocavam em movimento. A burguesia já não tinha mais que se preocupar com o feudalismo, mas com o socialismo.

Na passagem do século XX, o movimento Escola Nova defende uma pedagogia de satisfação das necessidades individuais, uma pedagogia "ativa" ou do "interesse", que conforme seus adeptos representasse para a educação uma "revolução coperniciana", o correspondente ao que teria representado na Idade Moderna a teoria heliocêntrica de Nicolau Copérnico para a Física. Tal revolução consistiria na mudança do centro de gravidade do professor e dos objetos de ensino para a criança e sua atividade. (BLOCK, 1951). Desse 
modo, o papel de formação de emancipação humana atribuído à educação pela maioria dos filósofos iluministas foi substituído pelo de satisfação das necessidades da criança, uma educação que prolongasse a linha de suas experiências atingindo os fins originados em suas necessidades, que se apresentava como "funcional", assentada na tese de Claparè de segundo a qual " [...] a verdadeira pedagogia consiste em exercitar uma atividade da criança conforme sua necessidade natural”. (BLOCK, 1951, p. 40).

A filosofia da escola nova tinha um sentido pragmático na medida em que consistia numa adequação da escola às necessidades da sociedade industrial propondo o livre desenvolvimento da criança a partir dos seus dons naturais. Era uma filosofia alinhada com o ideário liberal clássico segundo o qual no plano da economia se deve dar livre desenvolvimento às inclinações e disposições individuais. A defesa da iniciativa da criança a partir dos seus interesses correspondia à defesa da livre iniciativa pelo liberalismo, $\mathrm{o}$ resultado para ambas seria a sociedade democrática.

No contexto brasileiro da Ditadura Militar (1964-1985) ganha corpo na educação a pedagogia tecnicista vinculada ao objetivo de formação de capital humano, originária dos Estados Unidos da América. Convém invocar a apreciação crítica de Dermeval Saviani segundo a qual a escola ganha evidência para os defensores da teoria do capital humano "[...] uma vez que consideram que a educação é funcional ao sistema capitalista não apenas ideologicamente, mas também economicamente enquanto qualificadora da mão-de-obra (força de trabalho)". (SAVIANI, 1994, p. 152).

No contexto da globalização e de afirmação do pensamento neoliberal reafirma-se, o sentido pragmático da educação escolar por meio de orientações pedagógicas ancoradas no lema "aprender a aprender", na mesma perspectiva da filosofia escolanovista. A exemplo do que ocorreu em São Paulo.

No estado de São Paulo, a Secretaria de Educação desenvolveu concomitante à aplicação das medidas neoliberais que ensejaram a precarização e desvalorização do trabalho docente, conforme analisado no tópico anterior, uma orientação pedagógica de cunho neoliberal assentando-se na tese de que o objetivo da educação escolar deve ser o de formar competências para a vida, respondendo assim às novas necessidades de um mercado globalizado, extremamente competitivo e exigente. Lembrem que os escolanovistas propunham responder às exigências da sociedade industrial e democrática.

Neste estado brasileiro foram adotados vários programas e projetos inseridos na perspectiva construtivista dos quais cabe destaque o Programa Ler e Escrever, orientado às séries iniciais do ensino fundamental, e o Projeto São Paulo faz Escola, para as quatro últimas séries do ensino fundamental e para o ensino médio, ambos implementados a partir de 2008.

Acerca do material adotado pelo Programa Ler e Escrever, Marsiglia (2011, p. 191) conclui “"...] que os conteúdos são esparsos, desconexos, com pouca profundidade e visam conhecimentos particulares em detrimento daqueles universais".

Quanto ao São Paulo Faz Escola, este foi implementado por meio de cadernos do aluno e cadernos do professor estruturados exclusivamente pelas chamadas "situações de aprendizagem", a partir de fundamentos teórico-metodológicos pré-estabelecidos, assim como é predefinido a quantidade de aulas que deverá ser destinada para cada "situação". 
Artigo

doi: $10.20396 /$ rho.v17i4.8651218

Sendo assim, a concepção teórica que deve sustentar a atividade docente, assim como os objetos de ensino são determinados pelo material. Cabendo uma observação acerca da forma como a orientação pedagógica paulista se instrumentaliza nas chamas situações de aprendizagem, temos a considerar que estas foram elaboradas por equipes externas à escola, sem a participação do professor que deve aplica-la, ao passo que na proposição construtivista original estas deveriam ser elaboradas por estes professores, conforme Philippe Perrenoud (2000), autor que figura há muitos anos nas bibliografias obrigatórias nos concursos de ingresso para a carreira docente na rede estadual paulista, para quem a primeira competência para ensinar deveria ser a de organizar e dirigir situações de aprendizagem, e não recebê-las prontas. Tal observação não significa a defesa da tese construtivista de se educar por meio de situações de aprendizagens, pois discordamos da mesma, mas que a orientação pedagógica da Secretaria de Educação do Estado de São Paulista encerra contradições relativamente aos postulados que diz defender.

Porém, a questão da incoerência ou mesmo inconsistência da orientação pedagógica aplicada na rede paulista não constitui objeto deste estudo, mas sim a coerência de tal orientação com o ideário neoliberal. No âmbito pedagógico o Estado de São Paulo atribui à educação escolar a tarefa de adaptar os indivíduos à logica do mercado, descaracterizando a escola relativamente a sua finalidade de ensinar e formar intelectualmente as futuras gerações; no âmbito administrativo impõe medidas de precarização da profissão docente e da escola pública aplicando as orientações do Consenso de Washington com o fim de moldar o Estado aos desígnios do capital e do mercado mundial.

A implementação da orientação pedagógica construtivista na rede oficial de ensino do Estado de São Paulo, com o consequente cerceamento de outras orientações alternativas, caminhou em sintonia com as medidas administrativas de reestruturação da educação básica. Ambas decididas no âmbito governamental geralmente com o concurso de assessorias externas à rede de ensino e impostas posteriormente por meio de portarias, resoluções e comunicados. Os professores, quando foram chamados sempre o foi com o fim de receberem informações pertinentes ao cumprimento das orientações, na realidade imposições.

A vinculação entre orientação pedagógica e orientação administrativa neoliberal na rede de ensino paulista pode ser percebida de forma explícita -desde que se queira ver, obviamente -no modelo de gestão escolar que se estrutura a partir de um conjunto de funções atribuídas a professores afastados da atividade docente propriamente dita com o intuito principal de estabelecer formas de controle sobre os professores que atuam em sala de aula e fazê-los cumprir as normas pedagógicas e administrativas.

Chama-se de função na rede oficial paulista àquelas atividades que não estão vinculadas a um cargo concursado. Nas unidades escolares os cargos concursados da carreira do magistério são os de docente, numa ponta, e direção de escola, na outra; de modo que as funções intermediárias são exercidas mediante designação temporária por parte da direção da escola ou da diretoria de ensino que representa politicamente o Governo também por meio de função designada.

As funções intermediárias no âmbito das escolas e que se impõem como controle sobre os docentes em exercício são: vice-direção, coordenação de sala de leitura, responsável pelo Projeto Escola da Família, desenvolvido aos finais de semana, (com grau de vice-direção) mediadores de conflito e professor coordenador (existem outras funções 
designadas no âmbito das diretorias de ensino e Secretaria da Educação). Em grande parte das escolas existe em torno de dois ocupantes para cada uma destas funções, de modo que em uma escola com aproximadamente quatro dezenas de professores em sala de aula pode existir até uma dezena de outros profissionais para controla-los sob a aura de "suporte pedagógico". Acresce dois fatos: primeiro, que as funções de mediador de conflitos, escola da família e sala de leitura não podem ser designadas a professores efetivos, sendo assim, ao designar a função a um professor com regime de contratação temporário aumenta o poder de pressão para que o mesmo cumpra sem questionamentos tal função; segundo, os profissionais designados recebem gratificações, percebendo assim remuneração maior do que o docente que ministra aulas; terceiro, afastados da sala de aula não ficam sujeitos aos eventuais transtornos em decorrência da superlotação das salas de aula e jornadas de trabalho insalubres.

\section{PEDAGOGIA HISTÓRICO-CRÍTICA: CONTRA A DESCARACTERIZAÇÃO DA ESCOLA E A ALIENAÇÃO DO TRABALHO DOCENTE}

Nos dois tópicos anteriores procedemos à crítica da reforma neoliberal do Estado e da Educação e da descaracterização da escola pública que a acompanha a partir de uma abordagem referenciada na concepção materialista e dialética da história que está, por sua vez, na base da Pedagogia Histórico-Crítica. Neste tópico daremos prosseguimento à crítica da política educacional da Secretaria de Educação do Estado de Paulo ancorados nos pressupostos da Pedagogia Histórico-Crítica que se relacionam às concepções de indivíduo, de trabalho docente e de alienação, concepções que explicitaremos com o desenrolar de nossa exposição.

Partimos da caracterização de que o conhecimento elaborado constitui um patrimônio cultural da humanidade e que o pensamento burguês o valorizou como instrumento da luta contra a resistência feudal ao desenvolvimento das forças produtivas que o capitalismo coloca-se em movimento. Mas ao consolidar-se no poder deixou de se estimular o pleno desenvolvimento das ciências e orientou para o conhecimento instrumental para o capital e para os propósitos político-ideológicos da burguesia. A desvalorização do conhecimento constitui o principal traço da decadência ideológica do pensamento burguês e é acompanhado da fragmentação das ciências, da apologia do capitalismo e da desconfiança com relação à razão e à possibilidade de se alcançar um conhecimento objetivo sobre a realidade, principalmente a realidade humano-social. Neste contexto desenvolve-se na filosofia o relativismo e o irracionalismo.

As pedagogias escolanovistas, que se situam no contexto da decadência do pensamento burguês, carregavam elementos relativistas alinhados com certa dose de naturalização das características humanas que se impõem a partir da vida social (necessidades, interesses, dons, etc.). As pedagogias que Duarte (2001) denomina de "aprender a aprender", sobretudo no contexto do avanço do ideário neoliberal e fundamentada no chamado pensamento pós-moderno, reafirmam e aprofundam o relativismo e a crítica à razão. 


\title{
Revista HIIST'TEIDBR On-line
}

A vinculação entre as pedagogias do aprender a aprender e pensamento burguês neoliberal não deve ser entendida no plano moral, mas objetivo, pois independente das finalidades políticas e ideológicas dos autores construtivista e pós-modernos, suas proposições reforçam no âmbito escolar a tendência à desvalorização do conhecimento e consequentemente de descaracterização da finalidade da instituição escolar perseguido pelo ideário burguês há mais de um século e acentuado com a emergência do neoliberalismo. Por isso que no caso particular do Estado de São Paulo os governos promotores das reformas assume tal orientação pedagógica como oficial e cerceia as alternativas contra hegemônicas.

Num quadro de precarização e de descaracterização da escola pública e do trabalho docente, como o observado no estado de São Paulo, há que se pensar nas consequências produzidas sobre a formação da personalidade do professor, deste professor que se encontra na encruzilhada entre aceitar acriticamente a linha pedagógica oficial, assim como tudo o que lhe ordenam os seus superiores hierárquicos, ou resistir num contexto totalmente adverso.

\begin{abstract}
A pressão sobre o professor para que adote uma orientação pedagógica em detrimento de outra gera insatisfação e frustração, interferindo negativamente nas condições de trabalho. A insatisfação e a frustração do professor frente à dificuldade, e às vezes até mesmo à impossibilidade de ensinar o objeto de sua disciplina, coloca-o frente a dois caminhos: rebelar-se, mantendo a forma de ensinar que ele entende ser a mais correta [...] ou aceitar acriticamente todo o receituário que lhe é imposto pela política oficial como forma de sobrevivência, $o$ que nos remete à alienação do trabalho. (DERISSO, 2013, p. 53).
\end{abstract}

Para se compreender o processo de alienação há que se compreender antes a centralidade do trabalho no processo de formação do gênero humano.

Numa abordagem superficial, o trabalho poderia assemelhar-se à atividade de subsistência existente em todo reino animal, mas na forma especificamente humana o trabalho distingue-se radicalmente das atividades dos demais animais. Para Marx, toda espécie animal possui uma atividade vital por meio da qual os integrantes dessa espécie asseguram sua sobrevivência. A atividade vital humana tem peculiaridades não encontradas na atividade vital de nenhuma outra espécie. Entre essas peculiaridades destacam-se o caráter consciente e a produção de meios para satisfação das necessidades.

$\mathrm{Na}$ atividade do trabalho o produto desenha-se na mente do trabalhador antes mesmo que a ação se efetive. É como se a atividade se realizasse duas vezes, uma em projeto e outra de fato. Neste sentido o trabalho é uma atividade consciente e "teleológica", pois tem fim pré-determinado. Ao mesmo tempo, entretanto, se o ser humano colocar para sua atividade fins que não possam ser objetivamente alcançados, certamente fracassará na satisfação de suas necessidades. Isso quer dizer que na atividade de trabalho o ser humano estabelece uma relação entre os fins almejados e os meios para se alcançarem esses fins. Ocorre que entre os meios dos quais dispõe para realizar sua atividade, o ser humano conta com produtos da atividade previamente realizada por ele mesmo ou por outras pessoas, ou seja, dispõe de instrumentos. Isso confere à atividade humana uma característica decisiva, a de ser uma atividade mediada. $\mathrm{O}$ caráter mediado da atividade de trabalho explica a transformação histórica das necessidades humanas, ou seja, explica a transformação histórica do mundo humano, do mundo da cultura. Pensemos que se o homem não trabalhasse e sobrevivesse por meio de caça e coleta espontânea, como os grandes mamíferos, não haveria elementos 


\section{Revista HIISTEYIDIR On-line}

Artigo

doi: $10.20396 /$ rho.v17i4.8651218

culturais a serem transmitidos às futuras gerações, e nesse sentido não existiria qualquer forma de memória social, não haveria história social apenas individual. É baseado neste entendimento que Marx e Engels (1980, p. 33) observam:

[...] devemos lembrar de um primeiro pressuposto de toda existência humana e, portanto, de toda a história, a saber, que os homens devem estar em condições de poder viver a fim de "fazer história". Mas, para viver, é necessário antes de mais beber, comer, ter um teto onde se abrigar, vestir-se, etc. O primeiro fato histórico é, pois, a produção dos meios que permitem satisfazer essas necessidades, a produção da própria vida material; trata-se de um fato histórico, de uma condição fundamental de toda a história, que é necessário, tanto hoje como há milhares de anos, executar dia a dia, hora a hora, a fim de manter os homens vivos.

Feita esta consideração sobre o trabalho e sua relação com o processo de formação do gênero humano como ser social passemos para a questão da alienação.

A alienação se manifesta, grosso modo, como um estranhamento do indivíduo para com os aspectos da vida social e deve ser pensada como processo de base histórico-social, porque se origina nas relações econômicas.

O processo de alienação na sociedade capitalista desenvolvesse a partir de alguns momentos. O primeiro momento é a alienação do indivíduo para com o produto do seu trabalho, levando a que o mesmo identifique o trabalho com uma atividade estranha e adversa e não mais como a atividade vital humana. Os momentos intermediários da alienação podem ser identificados na relação de estranhamento do indivíduo para com o processo de trabalho no qual se vê obrigado a inserir-se sem compreendê-lo e com o conhecimento técnico e científico cuja identificação com o processo de trabalho também não é compreendido por este mesmo indivíduo. O momento culminante do processo de alienação é aquele no qual o indivíduo deixa de se identificar com o próprio gênero humano, por não entender sua especificidade de ser social (histórico-cultural), nesta fase o estranhamento se manifesta para com as expressões superiores do conhecimento humano (ciência, a filosofia e arte) e também para com o conjunto das relações sociais, ou seja, com o produto do conhecimento e formas de organização que a sociedade humana incorporou no processo histórico do qual o trabalho constitui o primeiro fato imaginável. A decorrência do processo de alienação a partir deste momento culminante é a falsa consciência de que a sociedade constitui um ambiente adverso no qual se deve sobreviver e que as regras de convívio social, a solidariedade, o respeito humano, a fraternidade são imposições externas a serem toleradas ou praticadas conforme a conveniência, tanto que o idealismo as apresenta como resultantes de contrato social celebrado por nossos ancestrais ou mesmo, às vezes os dois juntos, por força da religião.

Esta definição que é corrente nos estudos sobre a alienação na perspectiva do materialismo histórico e dialético contrapõe-se à concepção idealista que concebe a alienação como um fenômeno subjetivo, um estado de espírito, cuja superação demanda um esforço estritamente individual. A alienação se manifesta no indivíduo e interfere na formação de sua personalidade, mas é um fenômeno social cuja superação passa pela identificação do alcance social e das possibilidades históricas de superação. Numa palavra: romper com a alienação é engajar-se na luta pela sociedade alienada.

Para abordar a alienação do professor faz-se necessário identificar que a 


\section{Revista HIISTEYIDIR On-line}

especificidade de seu trabalho consiste no tratamento que este confere ao conhecimento humano. Nas mãos do professor o conhecimento humano acumulado e sistematizado deve ser transformado em conhecimento escolar pela mediação da didática (elaboração de currículo, adequado às especificidades dos alunos, e organização dos meios de execução da atividade de ensino). A atividade docente somente se realiza em sentido pleno na medida em que os alunos são elevados do nível do cotidiano alienado para o do conhecimento elaborado, aquele conhecimento que o processo de trabalho na sociedade de classes desvincula da vida dos trabalhadores. Por isso é correto dizer que a atividade educativa produz humanização, ou seja, reata o vínculo rompido pela alienação entre o indivíduo e o gênero humano. Ao passo que a alienação do trabalho docente consiste justamente na impossibilidade de realizar esta humanização. Com magistral precisão Dermeval Saviani (2005, p. 13) definiu o caráter do ato educativo e, por conseguinte, da atividade docente:

O trabalho educativo é o ato de produzir, direta e intencionalmente, em cada indivíduo singular, a humanidade que é produzida histórica e coletivamente pelo conjunto dos homens. Assim, o objeto da educação diz respeito, de um lado, à identificação dos elementos culturais que precisam ser assimilados pelos indivíduos da espécie humana para que eles se tornem humanos e, de outro lado e concomitantemente, à descoberta das formas mais adequadas para atingir esse objetivo.

Compreendemos, portanto, que as pedagogias do aprender a aprender que fundamentam as orientações pedagógicas hegemônicas contribuem para a alienação do trabalho docente na medida em que exaltam o conhecimento cotidiano e objetivam a adequação dos alunos à realidade e às exigências do mercado de trabalho. Deste modo descaracterizam o trabalho do professor em sala de aula e, consequentemente, o papel social da própria escola. Sob a obrigação de aplicar tais orientações, conforme ocorre na rede oficial de ensino do Estado de São Paulo, o professor deixa de reconhecer-se na atividade que realiza porque esta se torna adversa e pesarosa, repercutindo no plano psicológico de modo a contribuir para o aumento de doenças laborais de cunho psicológico.

\section{CONSIDERAÇÕES FINAIS}

Baseados nos pressupostos teórico-metodológicos da Pedagogia Histórico-Crítica principalmente a partir da compreensão do significado histórico do conhecimento elaborado e de sua referência para a educação escolar, da necessidade de combater a alienação e de superar a sociedade alienada por uma sociedade socialista - identificamos que a imposição das medidas neoliberais significa um retrocesso no plano das conquistas sociais no que tange à qualidade de vida e seguridade dos trabalhadores; quando aplicadas à educação retiram direitos do magistério e precarizam o trabalho docente; e quando combinadas com as pedagógicas do aprender a aprender reforçam nos educandos os traços idealistas, subjetivistas e individualistas acentuando, assim, o processo de alienação que se impõe na sociedade capitalista em função do modo pelo qual a produção social se organiza.

Neste sentido compete à Pedagogia Histórico-Crítica desenvolver a crítica das formas de gestão impostas pelas políticas neoliberal e simultaneamente aprofundar o enfrentamento com as pedagogias que enaltecem os ideais neoliberais na educação. 


\section{BIBLIOGRAFIAS}

BLOCK, A. Filosofia da escola nova. São Paulo: Companhia Editora Nacional, 1951.

DEITOS. R. A. A ideologia do desenvolvimento e da globalização e as proposições curriculares elaboradas. In: FIGUEIREDO, I. M. Z.; ZANARDINI, I. M. S.; DEITOS, R. A. Educação, políticas sociais e estado no Brasil. Cascavel: Ed. da EDUNIOESTE; Curitiba: Fundação Araucária, 2008.

DERISSO, J. L. Luta de classes, trabalho docente e pedagogia histórico-crítica na educação escolar. Germinal: Marxismo e Educação em Debate, Salvador, v. 5, n. 2, p. 4758, dez. 2013.

DUARTE, N. As pedagogias do "aprender a aprender" e algumas ilusões da assim chamada sociedade do conhecimento. Revista Brasileira de Educação, Rio de Janeiro, ANPED, n. 18, p. 35-40, set./dez. 2001.

G1 SÃO CARLOS E ARARAQUARA. 40\% dos professores afastados por saúde têm depressão. 10 out. 2012. Disponível em: <http://g1.globo.com/sp/sao-carlos-regiao/ noticia/2012/10/40-dos-professores-afastados-por-saude-tem-depressao-apontaestudo.html>. Acesso em: 26 jul. 2017.

LÖWY, M. As aventuras de Karl Marx contra o Barão de Müchhausen: marxismo e positivismo na sociologia do conhecimento. 9. ed. São Paulo: Cortez, 2009.

LUIZ, G. Piso salarial dos professores terá reajuste de $11,36 \%$ em 2016. G1:

Educação. Brasília. 14 jan. 2016. Disponível em: <http://g1.globo.com/educacao/noticia/ 2016/01/piso-salarial-dos-professores-tera-reajuste-de-1136-em-2016-diz-mec.html>. Acesso em: 24 mar. 2017.

LUKÁCS, G. Marxismo e teoria da literatura. São Paulo: Expressão Popular, 2010.

MARSIGLIA, A. C. G. Um quarto de século de construtivismo como discurso pedagógico oficial na Rede Estadual de Ensino Paulista: análise de programas e documentos da Secretaria de Estado da Educação no período de 1983 a 2008. 2011. Tese (Doutorado em Educação Escolar) - Universidade Estadual Paulista, Araraquara, 2011.

MARX, K.; ENGELS, F. A ideologia alemã. Tradução de Conceição Jardim e Eduardo Lucio Nogueira. 4. ed. Portugal: Presença; São Paulo: Martins Fontes, 1980.

PERRENOUD, P. 10 novas competências para ensinar. Porto Alegre: ArtMed, 2000.

PINTO, J. M. R. Remuneração adequada do professor desafio à educação brasileira.

Revista Retratos da Escola, Brasília, v. 3, n. 4, p. 1-302, jan./jun. 2009. Disponível em: <http://www.cnte.org.br/index.php/publicacoes/retratos-da-escola/14360-retratos-daescola-volume-3-numero-4-janeiro-a-junho-de-2009.html>. Acesso em: 24 mar. 2017. 
SÃO PAULO (Estado). Secretaria da Educação. A Sociedade Órfã. Produção de José Renato Nalini, secretário da Educação do estado de São Paulo. Portal do Governo. 05/04/16. Disponível em: 〈http://www.educacao.sp.gov.br/noticias/a-sociedade-orfa>. Acesso em: 28 mar. 17.

SAVIANI, D. Escola e democracia. 31. ed. Campinas: Autores Associados, 1997. (Polêmicas do Nosso Tempo, v. 5).

SAVIANI, D. O trabalho como princípio educativo frente as novas tecnologias. In: FERRETTI, C. J. et al. (Org.). Novas tecnologias, trabalho e educação: um debate multidisciplinar. Petrópolis: Vozes, 1994.

SAVIANI, D. Pedagogia histórico-crítica: primeiras aproximações. 5. ed. São Paulo: Autores Associados, 2005.

TAKAHASHI, F. Rede estadual de SP enfrenta saída recorde de professores. Folha de São Paulo, São Paulo, 17 nov. 2015. Disponível em: <http://www1.folha.uol.com.br/educacao/ 2015/11/1707366-rede-estadual-de-sp-enfrenta-saida-recorde-de-professores.shtml > Acesso em: 22 fev. 2015.

TORRES, R. M. Melhorar a qualidade da educação básica? As estratégias do Banco Mundial. In: DE TOMMASI, L.; WARDE, M. J.; HADDAD, S. (Org.). O Banco Mundial a as políticas educacionais. 3. ed. São Paulo: Cortez, 2000.

ZANARDINI, J. B. A ideologia do Desenvolvimento e da globalização e as proposições curriculares elaboradas. In: FIGUEIREDO, I. M. Z.; ZANARDINI, I. M. S.; DEITOS, R. A. Educação, políticas sociais e estado no Brasil. Cascavel: Ed. da EDUNIOESTE; Curitiba: Fundação Araucária, 2008.

\section{Notas}

\footnotetext{
${ }^{1}$ Professor Adjunto de Fundamentos da Educação na UNIOESTE - Cascavel/PR; Doutor em Educação Escolar; Membro do grupo de pesquisa "Estudos Marxistas em Educação" da UNESP/ Araraquara e do Grupo de Estudos e Pesquisas em "História, Sociedade e Educação no Brasil" - GT da Região Oeste do Paraná "HISTEDOPR"; E-mail: joseluisderisso@yahoo.com.br

${ }^{2}$ Doutoranda do Programa de Pós-Graduação em Educação Escolar na UNESP Araraquara e Membro do grupo de pesquisa "Estudos Marxistas em Educação", da Universidade Estadual Paulista Júlio de Mesquita Filho. Bolsista CAPES/CNPQ. E-mail: ritaduartederisso@yahoo.com.br
}

Submetido em: 13/11/2017

Aprovado em: 13/12/2017 